\title{
Nerve growth factor variations in patients with mood disorders: no changes in eight weeks of clinical treatment
}

This article was published in the following Dove Press journal:

Neuropsychiatric Disease and Treatment

15 May 2014

Number of times this article has been viewed

\author{
Xiaohua Liu',* \\ Tianhong Zhang ${ }^{1, *}$ \\ Shen $\mathrm{He}^{l}$ \\ Bo Hong' \\ Daihui Peng' \\ Hui Su' \\ Fei $\mathrm{Li}^{\prime}$ \\ Yingying Tang' \\ Zhiguang Lin $^{2}$ \\ Yiru Fang' \\ Kaida Jiang' \\ 'Department of Psychiatry, \\ Shanghai Mental Health Center, \\ Shanghai Jiao Tong University School \\ of Medicine, Shanghai, ${ }^{2}$ Biochemistry \\ laboratory, Shanghai Mental Health \\ Center, Shanghai Jiao Tong University \\ School of Medicine, Shanghai, People's \\ Republic of China \\ *These authors contributed equally \\ to this work
}

Correspondence: Kaida Jiang; Xiaohua Liu Shanghai Mental Health Center, 600 South Wanping Road, Shanghai 200030, People's Republic of China

$\mathrm{Tel}+862 \mathrm{I} 64860502$

Fax +86 21 64387986

Email jiangkaida@sina.com;

drliuxiaohua@gmail.com
Background: Nerve growth factor (NGF) has received much attention for its role in mood disorders. The primary objective of the present study was to examine serum NGF levels in Chinese inpatients with depressive or manic episodes in the acute phase and to explore the changes in NGF levels after effective clinical treatments.

Methods: One hundred and seven consecutive inpatients and outpatients with mood disorders (30 with unipolar depression, 23 with bipolar depression, and 54 with bipolar mania), and 50 healthy controls were recruited. The serum NGF levels were detected by enzyme-linked immunosorbent assay.

Results: Patients with bipolar mania presented higher serum NGF levels compared to those of healthy controls. After 8 weeks of medical treatment, there were significant improvements in symptoms in patients, but no significant changes in NGF levels.

Conclusion: The present findings may help to strengthen and expand the understanding of the role of NGF in the acute stages of mood disorders.

Keywords: neurotrophins, depression, mania, bipolar disorder, acute phase, clinical sample

\section{Introduction}

Nerve growth factor (NGF), one of the essential neurotrophic factors (NF), has received much attention due to its neuroprotective effects on cholinergic neurons in Alzheimer's disease research. ${ }^{1,2}$ Recently, some mouse models of anxiety vulnerability, stress-induced illness, and depression involving learned helplessness, threatening treatment (with painful stimuli), maternal deprivation, and other factors have shown decreased levels of NGF in the frontal cortex, amygdala, hippocampus, and nucleus accumbens. ${ }^{3-5}$ Together with brain-derived neurotrophic factor and other NFs, NGF has been shown to be involved in the regulation of neurogenesis, regulation of differentiation, and the plasticity of neuronal networks. ${ }^{6,7}$ It has been suggested that these mechanisms could be modified by serotonin, norepinephrine, and acetylcholine.$^{8-10}$ Thus, preclinical research studies have suggested that NGF potentially plays an important role in the development of mood disorders, as well as in recovery during the clinical treatment process.

However, the levels of NGF have been shown across many clinical investigations to be rather varied among patients with mood disorders. ${ }^{11-15}$ It has been reported that plasma NGF level decreases in both depression and bipolar mania; ${ }^{11}$ however, others have not found any differences between patients suffering with depression and healthy controls. ${ }^{16}$ Whether NGF variations are a state- or trait-related phenomenon remains contentious. A state-related phenomenon of mood disorders is a characteristic that appears and disappears with clinical episodes, such as depression or mania. In contrast, 
a trait-related phenomenon occurs regardless of variations in the clinical state. Mood disorders are highly heterogeneous and complex disorders. The clinical profiles and related treatments could be a critical component in deciding whether there is heterogeneity in serum NGF levels among patients with mood disorders.

There is still little information on serum NGF levels in patients experiencing the initial stages of depressive or manic episodes in clinical settings. Patients with more severe symptoms, such as suicidal ideas or aggressive behaviors, have often been excluded in previous studies, and this may potentially influence the findings. The primary objective of the present study was to examine serum NGF levels in Chinese inpatients with depressive or manic episodes in the acute phase. Furthermore, as few studies have explored the changes in NGF levels after effective clinical treatments, there is a need for the collection of detailed clinical profiles and NGF levels both at baseline and after treatment in patients with acute depressive or manic episodes.

\section{Methods}

\section{Subjects}

One hundred and seven consecutive inpatients and outpatients with diagnoses of mood disorders who visited the Shanghai Mental Health Center were recruited according to the following inclusion criteria: 1) age 18-65 years; 2) meeting the Diagnostic and Statistical Manual of Mental Disorders, 4th edition (DSM-IV) criteria for unipolar depression, bipolar depression, or bipolar mania based on the Structured Clinical Interview for DSM Disorders/Patient edition (SCID-I/P); 3) inpatients with first or recurrent major depressive or manic episodes, who were drug-naïve or drugfree for at least 4 weeks; and 4) the ability to give written consent. The exclusion criteria included the following: medical illness, such as chronic diseases, including diabetes and any infectious disease in the month prior to enrollment; pregnancy; substance abuse; and a history of relevant medicines, such as antibiotics and antioxidants in at least the previous 4 weeks. Physical examinations and routine standard laboratory tests for inpatients helped to exclude subjects with medical comorbidities and concomitant medications. At baseline, 50 healthy controls (volunteers from the community) were recruited. After they provided written consent, they were assessed with the SCID-I/NP to confirm that they had no past or present mental disorders. They underwent the same procedure of enrollment screening and followed the similar inclusion (except for criteria 2 and 3 ) and exclusion criteria as patients.

\section{Procedures}

Five milliliters of blood was drawn by venipuncture into an anticoagulant-free tube between 7 am and 8 am after an overnight fast. The blood was centrifuged at $3,000 \times g$ for $20 \mathrm{~min}$ at $4^{\circ} \mathrm{C}$ within 2 hours of collection. After collection, the serum was separated and stored at $-80^{\circ} \mathrm{C}$ until it was assayed. Serum NGF levels were measured with an enzymelinked immunosorbent assay (ELISA) method according to the manufacturer's instructions, using a ChemiKineTM NGF Sandwich ELISA Kit (Catalog\#: CYT304, EMD Millipore Corporation, Billerica, MA, USA). The intra- and inter-assay coefficients of variation were less than $9 \%$. The limit of detection was $1 \mathrm{pg} / \mathrm{mL}$, and the concentration of NGF was expressed as $\mathrm{pg} / \mathrm{mL}$.

All inpatients and outpatients were screened and assessed by two senior psychiatrists. The severity of manic symptoms was measured with the Bech-Rafaelsen Mania Rating Scale (BRMS) and the Young Mania Rating Scale (YMRS), and depressive symptoms were measured with the 24-item Hamilton Depression Scale (HAM-D), the Hamilton Anxiety Scale (HAM-A), and the Montgomery-Asberg Depression Rating Scale (MADRS). The agreement rate between the two psychiatrists was $0.78-0.91$, expressed as a kappa value. The detailed demographic and clinical information was collected from all of the subjects with a face-to-face interview. The same clinical assessments, blood collection, and laboratory procedures were performed again at week 8 for all the patients.

\section{Statistical analysis}

SPSS version 16.0 (SPSS Inc., Chicago, IL, USA) statistical software was used for all statistical computations. The sociodemographic and clinical characteristics of the samples were presented as descriptive statistics, such as percentage and mean scores. One-way analysis of variance (ANOVA) was used to test between group comparisons for continuous variables, as applicable. For the group comparisons of categorical variables, the chi-squared test was used. Since the distribution of serum NGF level was not normal, a nonparametric Mann-Whitney test was used between groups. A box-plot diagram was created by the SPSS software to show the differences in the plasma NGF levels among the following four groups: unipolar depression; bipolar depression; bipolar mania; and control groups. A line diagram was used to show the changes in serum NGF levels after 8 weeks of treatment. Significance was determined with $P$-values less than 0.05 (two-tailed). 


\section{Results}

The study sample consisted of 107 participants with mood disorders and 50 healthy controls. Of those, 30 (19.1\%) were diagnosed with unipolar depression, 23 (14.6\%) with bipolar depression, and 54 (34.4\%) with bipolar mania. The demographic and clinical features of all the subjects are shown in Table 1. A number of patients were treated with antidepressants (35), including paroxetine (6), fluoxetine (5), escitalopram (9), duloxetine (7), trazodone (4), sertraline (5), and mirtazapine (8). Nine patients were treated with two types of antidepressants. Seventy-seven patients were treated with mood stabilizers (valproate and lithium) or anticonvulsants (lamotrigine), and 47 patients had a combined treatment of antipsychotic medicines.

At baseline, patients with bipolar mania presented higher serum NGF levels (mean \pm standard deviation [SD]: 43.32 $\pm 32.76 \mathrm{pg} / \mathrm{mL}$, median: $38.05 \mathrm{pg} / \mathrm{mL}$ ) as compared to those of healthy controls (mean $\pm \mathrm{SD}: 36.34 \pm 15.14 \mathrm{pg} / \mathrm{mL}$, median: $32.22 \mathrm{pg} / \mathrm{mL})(Z=-2.427, P=0.015)$ and patients with unipolar depression (mean \pm SD: $33.18 \pm 7.42 \mathrm{pg} / \mathrm{mL}$, median: $30.82 \mathrm{pg} / \mathrm{mL})(Z=-2.288, P=0.022)$ (Figure 1). There was no significant difference in the serum NGF levels between the bipolar depression group (mean $\pm \mathrm{SD}$ : $44.00 \pm 44.00 \mathrm{pg} / \mathrm{mL}$, median: $36.59 \mathrm{pg} / \mathrm{mL}$ ) and the control group. After a thorough pairwise comparison, only the $P$-values with significant differences were listed in Figure 1. For all subjects, no associations were observed between serum NGF levels (Week 0) and age, age of first mood episode, or the duration of the present episode.

After 8 weeks of medical treatment, there were significant improvements in the HAM-D $(t=17.19, d f=52, P<0.001)$, HAM-A $(t=18.57, d f=52, P<0.001)$, and MADRS $(t=13.79$, $d f=52, P<0.001)$ scores in patients under depression and in the BRMS $(t=19.59, d f=53, P<0.001)$ and YMRS $(t=18.39$, $d f=53, P<0.001)$ scores in patients with mania, but no significant changes in NGF levels were observed among the patients (Figure 2). For all patients, there were no associations between serum NGF levels (Week 8) and age, age of first mood episode, or the duration of the present episode.

Similarly, at the end of 8 weeks' treatment, patients with mania presented higher serum NGF levels (mean $\pm \mathrm{SD}$ : $44.42 \pm 55.29 \mathrm{pg} / \mathrm{mL}$, median: $37.21 \mathrm{pg} / \mathrm{mL}$ ) as compared to patients with unipolar depression (mean $\pm \mathrm{SD}$ : $32.18 \pm 69.00 \mathrm{pg} / \mathrm{mL}$, median: $31.13 \mathrm{pg} / \mathrm{mL})(P=0.014)$, but no significant difference was found as compared to patients with bipolar depression (mean \pm SD: $43.73 \pm 34.09 \mathrm{pg} / \mathrm{mL}$, median: $35.86 \mathrm{pg} / \mathrm{mL}$ ).

Table I Demographic and clinical characteristics of patients versus healthy controls

\begin{tabular}{|c|c|c|c|c|c|}
\hline \multirow[t]{2}{*}{ Variables } & \multicolumn{3}{|c|}{ Mood disorders } & \multirow[t]{2}{*}{ Controls } & \multirow[t]{2}{*}{$P$-value } \\
\hline & $\begin{array}{l}\text { Unipolar } \\
\text { depression }\end{array}$ & $\begin{array}{l}\text { Bipolar } \\
\text { depression }\end{array}$ & Bipolar mania & & \\
\hline $\mathrm{N}$ & 30 & 23 & 54 & 50 & - \\
\hline Male (N, \%) & $10(33.3 \%)$ & $10(43.5 \%)$ & $21(38.9 \%)$ & $20(40.0 \%)$ & 0.892 \\
\hline Age (mean [SD]) & $47(13)$ & $45(15)$ & $39(14)$ & $37(\mathrm{II})$ & $0.003 * *$ \\
\hline Age of first mood episode (mean [SD]) & $40(12)$ & $34(13)$ & $27(\mathrm{II})$ & - & $0.000 * *$ \\
\hline Duration of present episode (weeks) (mean [SD]) & $15(20)$ & $15(12)$ & $7(10)$ & - & $0.022 *$ \\
\hline \multicolumn{6}{|l|}{ HAM-D (mean [SD]) } \\
\hline Week 0 & $28.0(8.07)$ & $28.7(6.55)$ & - & - & 0.726 \\
\hline Week 8 & $6.1(7.36)$ & $7.0(6.83)$ & - & - & 0.647 \\
\hline \multicolumn{6}{|l|}{ MADRS (mean [SD]) } \\
\hline Week 0 & $30.6(9.93)$ & $28.4(8.47)$ & - & - & 0.390 \\
\hline Week 8 & $3.8(5.48)$ & $4.2(4.24)$ & - & - & 0.782 \\
\hline \multicolumn{6}{|l|}{ HAM-A (mean [SD]) } \\
\hline Week 0 & 19.1 (7.34) & $21.1(9.44)$ & - & - & 0.390 \\
\hline Week 8 & $3.6(4.92)$ & $5.6(6.10)$ & - & - & 0.200 \\
\hline \multicolumn{6}{|l|}{ BRMS (mean [SD]) } \\
\hline Week 0 & - & - & $22.7(7.34)$ & - & - \\
\hline Week 8 & - & - & $2.3(2.22)$ & - & - \\
\hline \multicolumn{6}{|l|}{ YMRS (mean [SD]) } \\
\hline Week 0 & - & - & $29.6(10.72)$ & - & - \\
\hline Week 8 & - & - & $2.9(3.26)$ & - & - \\
\hline
\end{tabular}

Notes: $P$-value for comparison among groups was calculated by one-way analysis of variance (chi-squared test was used for comparing the proportions of sex among four groups). $* P<0.05 ; * * P<0.0$ I.

Abbreviations: SD, standard deviation; HAM-D, Hamilton Depression Scale; MADRS, Montgomery-Asberg Depression Rating Scale; HAM-A, Hamilton Anxiety Scale; BRMS, Bech-Rafaelsen Mania Rating Scale; YMRS, Young Mania Rating Scale. 


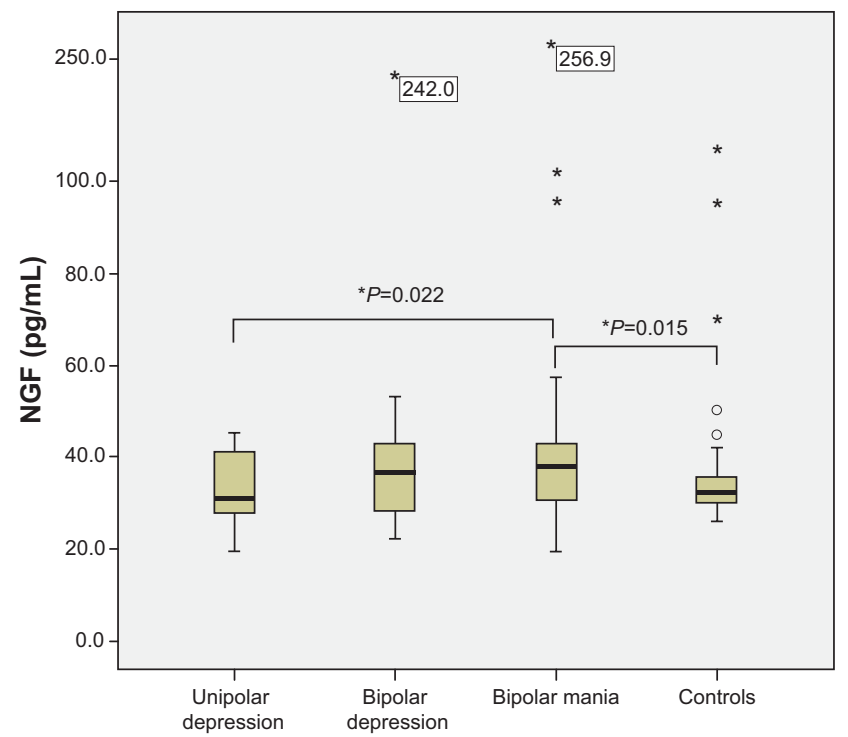

Figure I Box plot of the differences in serum nerve growth factor (NGF) levels among the different groups.

Notes: The $P$-values of the comparisons between the groups were calculated by the nonparametric Mann-Whitney test. $* P<0.05$.

\section{Discussion}

In this sample, the serum concentrations of NGF were significantly higher in subjects with bipolar mania than in subjects with unipolar depression and healthy controls. Curiously, after 8 weeks of intensive treatment, a significant improvement in clinical symptoms but no significant changes

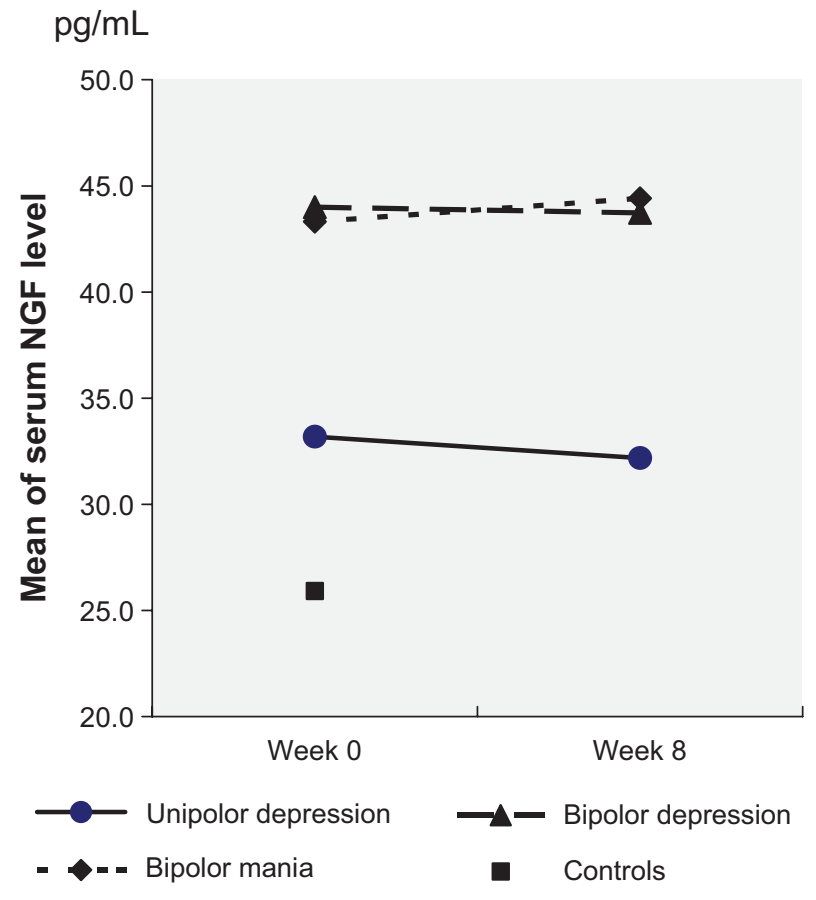

Figure 2 Mean nerve growth factor (NGF) value variations after 8 weeks of treatment of patients with unipolar depression, bipolar depression, or bipolar mania. in NGF levels were detected among the patients. The results of this study suggest that serum NGF levels are not sensitive to mood state but are more related to the cognitive domains of memory and attention. ${ }^{17}$ Corroborating our data, NGF protein levels in the hippocampus, amygdala, and nucleus accumbens of maternally deprived rats were not reversed by tianeptine treatment. ${ }^{5}$ In addition, a recent study has reported that maternal deprivation in rats led to reduced NGF levels in the hippocampus and amygdala. ${ }^{18}$

Several clinical studies have reported that serum NGF levels are decreased in patients with depression and that these levels are normalized by antidepressant treatment. ${ }^{19}$ However, we found no differences or changes in NGF levels in patients with depressive episodes and after 8 weeks of treatment. These results were consistent with Cirulli et a ${ }^{16}$ and Alleva et al's ${ }^{20}$ findings that patients with depression do not show any significant differences in NGF levels. Our explanation for the contradictory data is that NGF levels may not be directly responsive to depressive moods but are more related to stress from the mood state. NGF levels can increase due to hyperactivity of the hypothalamic-pituitaryadrenal axis caused by stress in the acute state ${ }^{21}$ however, chronic stresses can downregulate NGF levels. Thus, NGF seems to be a reaction to stress in the mood state rather than a potential biomarker that can predict a depressive state or the response to antidepressant treatment.

Serum NGF levels were higher in patients with bipolar manic episodes in our study. This may be associated with the highly psychological stressful state that patients experience during a manic episode. Many studies have reported higher NGF levels both in rats and humans in response to stressful events. ${ }^{22-25}$ Therefore, one could speculate that NGF might play a role in the neurobiological stress cascade. ${ }^{26}$ However, because it is well known that NGF levels correlate with cholinergic neurons, ${ }^{27}$ our findings suggest greater cholinergic involvement in patients with bipolar mania. ${ }^{28}$ However, in contrast to the lower levels of NGF in patients with bipolar mania reported by Barbosa et al ${ }^{11}$ we found higher levels among patients with mania in acute episodes. Distinct sociodemographic features (a younger pool of patients with mania in our study), clinical courses (a much shorter length of manic episodes in this study), and/or a control for medication (drug-free at baseline in our sample) might play a role in the different results in this study compared to the other studies.

Admittedly, several methodological limitations must be considered in regards to this study. Firstly, the lack of a control for the use of treatments of mood disorders, 
including antipsychotic and other medications, could have influenced the results. ${ }^{29-31}$ In addition, psychotic symptoms and cognitive impairments were not assessed. Thirdly, there was an age difference between the patients and healthy controls. Lastly, patients in euthymic states were not included. In this study, we included a representative sample in the initial stages of mood disorders, and the NGF levels were followed up 8 weeks after intensive treatment. Taken together, these results may help to strengthen and expand the understanding of the role of NGF in the initial stages of mood disorders. Additionally, the findings that are reported here represent the NGF levels of patients in a realistic clinical setting, and this may help to clarify the value of potential clinical implementation.

\section{Conclusion}

We demonstrated in this study that the serum NGF levels were higher in acute manic episodes in patients with bipolar disorder. No differences or changes in NGF levels were found after effective clinical treatments for mood disorders. These results suggest that the role of NGF may be involved in responding to stressful conditions, rather than predicting the mood state.

\section{Acknowledgments}

This work was supported by projects from SMCMorningstar Excellent Young Teachers (C plan) in Shanghai Jiao Tong University, Shanghai Health Bureau (2009098), National Natural Science Foundation of China (81000588, 61102020, 81201043), "Shanghai Health System Young Talents Training Plan" in Shanghai Health Bureau (XYQ2011016), Shanghai Municipal Natural Science Foundation (12ZR1448400), the National Key Clinical Disciplines at Shanghai Mental Health Center (OMA-MH, 2011-873) and Doctoral Innovation Fund Projects from Shanghai Jiao Tong University School of Medicine (BXJ 201345). We thank the patients and healthy volunteers for participation and the medical staff for collecting specimens. We are also grateful for the support from division of mood disorders in Shanghai Mental Health Center, Shanghai Jiao Tong University School of Medicine.

\section{Disclosure}

All authors declare that they have no conflicts of interest in this work.

\section{References}

1. Covaceuszach S, Capsoni S, Ugolini G, Spirito F, Vignone D, Cattaneo A. Development of a non invasive NGF-based therapy for Alzheimer's disease. Curr Alzheimer Res. 2009;6(2):158-170.
2. Tuszynski MH, Thal L, Pay M, et al. A phase 1 clinical trial of nerve growth factor gene therapy for Alzheimer disease. Nat Med. 2005;11(5):551-555.

3. Schulte-Herbruggen O, Chourbaji S, Muller H, et al. Differential regulation of nerve growth factor and brain-derived neurotrophic factor in a mouse model of learned helplessness. Exp Neurol. 2006;202(2): 404-409.

4. Schulte-Herbruggen O, Fuchs E, Abumaria N, et al. Effects of escitalopram on the regulation of brain-derived neurotrophic factor and nerve growth factor protein levels in a rat model of chronic stress. J Neurosci Res. 2009;87(11):2551-2560.

5. Della FP, Abelaira HM, Reus GZ, et al. Treatment with tianeptine induces antidepressive-like effects and alters the neurotrophin levels, mitochondrial respiratory chain and cycle Krebs enzymes in the brain of maternally deprived adult rats. Metab Brain Dis. 2013;28(1):93-105.

6. Sendtner M, Pei G, Beck M, Schweizer U, Wiese S. Developmental motoneuron cell death and neurotrophic factors. Cell Tissue Res. 2000;301(1):71-84.

7. Linker R, Gold R, Luhder F. Function of neurotrophic factors beyond the nervous system: inflammation and autoimmune demyelination. Crit Rev Immunol. 2009;29(1):43-68.

8. Hellweg R, Thomas H, Arnswald A, et al. Serotonergic lesion of median raphe nucleus alters nerve growth factor content and vulnerability of cholinergic septohippocampal neurons in rat. Brain Res. 2001; 907(1-2):100-108.

9. Rattray M. Is there nicotinic modulation of nerve growth factor? Implications for cholinergic therapies in Alzheimer's disease. Biol Psychiatry. 2001;49(3):185-193.

10. Counts SE, Mufson EJ. Noradrenaline activation of neurotrophic pathways protects against neuronal amyloid toxicity. $J$ Neurochem. 2010;113(3):649-660.

11. Barbosa IG, Huguet RB, Neves FS, et al. Impaired nerve growth factor homeostasis in patients with bipolar disorder. World J Biol Psychiatry. 2011;12(3):228-232.

12. Kapczinski F, Frey BN, Kauer-Sant'Anna M, Grassi-Oliveira R. Brain-derived neurotrophic factor and neuroplasticity in bipolar disorder. Expert Rev Neurother. 2008;8(7):1101-1113.

13. Diniz BS, Teixeira AL, Machado-Vieira R, Talib LL, Gattaz WF, Forlenza OV. Reduced serum nerve growth factor in patients with late-life depression. Am J Geriatr Psychiatry. 2013;21(5):493-496.

14. Ziegenhorn AA, Schulte-Herbruggen O, Danker-Hopfe H, et al. Serum neurotrophins - a study on the time course and influencing factors in a large old age sample. Neurobiol Aging. 2007;28(9):1436-1445.

15. Rybakowski JK, Permoda-Osip A, Skibinska M, Adamski R, Bartkowska-Sniatkowska A. Single ketamine infusion in bipolar depression resistant to antidepressants: are neurotrophins involved? Hum Psychopharmacol. 2013;28(1):87-90.

16. Cirulli F, Francia N, Branchi I, et al. Changes in plasma levels of BDNF and NGF reveal a gender-selective vulnerability to early adversity in rhesus macaques. Psychoneuroendocrinology. 2009;34(2):172-180.

17. Niewiadomska G, Mietelska-Porowska A, Mazurkiewicz M. The cholinergic system, nerve growth factor and the cytoskeleton. Behav Brain Res. 2010;221(2):515-526.

18. Reus GZ, Stringari RB, Ribeiro KF, et al. Maternal deprivation induces depressive-like behaviour and alters neurotrophin levels in the rat brain. Neurochem Res. 2011;36(3):460-466.

19. Martino M, Rocchi G, Escelsior A, et al. NGF serum levels variations in major depressed patients receiving duloxetine. Psychoneuroendocrinology. 2013;38(9):1824-1828.

20. Alleva E, Petruzzi S, Cirulli F, Aloe L. NGF regulatory role in stress and coping of rodents and humans. Pharmacol Biochem Behav. 1996;54(1):65-72.

21. Faure J, Uys JD, Marais L, Stein DJ, Daniels WM. Early maternal separation followed by later stressors leads to dysregulation of the HPA-axis and increases in hippocampal NGF and NT-3 levels in a rat model. Metab Brain Dis. 2006;21(2-3):181-188.

22. Della Seta D, de Acetis L, Aloe L, Alleva E. NGF effects on hot plate behaviors in mice. Pharmacol Biochem Behav. 1994;49(3):701-705. 
23. Aloe L, Bracci-Laudiero L, Alleva E, Lambiase A, Micera A, Tirassa P. Emotional stress induced by parachute jumping enhances blood nerve growth factor levels and the distribution of nerve growth factor receptors in lymphocytes. Proc Natl Acad Sci U S A. 1994;91(22):10440-10444.

24. Aloe L, Moroni R, Mollinari C, Tirassa P. Schistosoma mansoni infection enhances the levels of NGF in the liver and hypothalamus of mice. Neurorepor. 1994;5(9):1030-1032.

25. Maestripieri D, De Simone R, Aloe L, Alleva E. Social status and nerve growth factor serum levels after agonistic encounters in mice. Physiol Behav. 1990;47(1):161-164.

26. Cirulli F, Alleva E, Antonelli A, Aloe L. NGF expression in the developing rat brain: effects of maternal separation. Brain Res Dev Brain Res. 2000;123(2):129-134.

27. Korsching S, Auburger G, Heumann R, Scott J, Thoenen H. Levels of nerve growth factor and its mRNA in the central nervous system of the rat correlate with cholinergic innervation. EMBO J. 1985;4(6):1389-1393.
28. Sokolski KN, DeMet EM. Cholinergic sensitivity predicts severity of mania. Psychiatry Res. 2000;95(3):195-200.

29. Hassanzadeh $\mathrm{P}$, Rahimpour $\mathrm{S}$. The cannabinergic system is implicated in the upregulation of central NGF protein by psychotropic drugs. Psychopharmacology (Berl). 2011;215(1):129-141.

30. Martinotti G, Di Iorio G, Marini S, Ricci V, De Berardis D, Di Giannantonio M. Nerve growth factor and brain-derived neurotrophic factor concentrations in schizophrenia: a review. J Biol Regul Homeost Agents. 2012;26(3):347-356.

31. Pillai A, Terry AV Jr, Mahadik SP. Differential effects of longterm treatment with typical and atypical antipsychotics on NGF and BDNF levels in rat striatum and hippocampus. Schizophr Res. 2006;82(1):95-106.

\section{Publish your work in this journal}

Neuropsychiatric Disease and Treatment is an international, peerreviewed journal of clinical therapeutics and pharmacology focusing on concise rapid reporting of clinical or pre-clinical studies on a range of neuropsychiatric and neurological disorders. This journal is indexed on PubMed Central, the 'PsycINFO' database and CAS, and is the official journal of The International Neuropsychiatric Association (INA). The manuscript management system is completely online and includes a very quick and fair peer-review system, which is all easy to use. Visit http://www.dovepress.com/testimonials.php to read real quotes from published authors.

Submit your manuscript here: http://www.dovepress.com/neuropsychiatric-disease-and-treatment-journal 